\title{
Electrolyte content of milk differs in normotensive and spontaneously hypertensive rats
}

\author{
RICHARD MCCARTY, HONGYUN TONG, and ROBERT C. FORSYTHE \\ University of Virginia, Charlottesville, Virginia
}

\begin{abstract}
Milk samples were collected from lactating spontaneously hypertensive (SHR) and Wistar-Kyoto (WKY) normotensive females 14 days postpartum and were later analyzed for content of calcium $\left(\mathrm{Ca}^{++}\right)$, sodium $\left(\mathrm{Na}^{+}\right)$, potassium $\left(\mathrm{K}^{+}\right)$, chloride $\left(\mathrm{Cl}^{-}\right)$, magnesium $\left(\mathrm{Mg}^{++}\right)$, and total protein. Our findings revealed that milk samples from SHR females had significantly higher concentrations of $\mathrm{Na}^{+}$and $\mathrm{Cl}^{-}$and significantly lower concentrations of $\mathrm{Ca}^{++}, \mathrm{K}^{+}$, and protein when compared with samples from WKY females. In addition, the $\mathrm{Na}^{+} / \mathrm{K}^{+}$ratio for milk samples from SHR was significantly higher that that for samples from WKY. Milk levels of $\mathbf{M g}^{++}$were similar for females of the two strains. These results indicate that preweanling dietary content of several electrolytes implicated in the development of hypertension differs substantially between SHR and WKY pups. Such differences in milk electrolyte levels may constitute an important environmental trigger for age-related increases in arterial pressures of SHRs.
\end{abstract}

Rats of the inbred spontaneously hypertensive (SHR) and Wistar-Kyoto (WKY) normotensive strains have figured prominently in laboratory studies of blood pressure regulation over the past three decades (Geller, 1977; Lovenberg, Simpson, \& Yamori, 1986; Okomoto, 1972; Rascher, Clough, \& Ganten, 1982). Historically, much of the research with these and other hypertensive animal models has been preoccupied with documenting pathophysiological changes that attend the development of high blood pressure in adult animals or with utilizing these strains in preclinical tests of antihypertensive medications. In contrast, a recent focus of research with rodent models of human essential hypertension has been an examination of neonatal factors that influence the later development of high blood pressure (Blizard, 1992; DiNicolantonio, Imai, Murakami, \& Yamori, 1991; Gray, 1984).

In SHR and inbred Dahl hypertension-sensitive (SS/Jr) rats, factors associated with the maternal environment exert an important influence on the expression of the hypertensive phenotype. Specifically, studies from our laboratory and the work of others indicate that genetically hypertensive rats have significantly reduced basal blood pressures in adulthood when they were reared from birth to weaning by normotensive foster mothers. In contrast, the basal blood pressures of adult normotensive rats were

\footnotetext{
We thank John Savory and Gerry Savory, Clinical Chemistry Laboratory, Department of Pathology, University of Virginia Health Sciences Center for their advice and technical support. Robert E. Stewart provided helpful comments on an earlier draft. This study was supported in part by a grant from the American Heart Association-Virginia Affiliate, Inc. Correspondence should be addressed to Richard McCarty, Department of Psychology, 102 Gilmer Hall, University of Virginia, Charlottesville, VA $22903-2477$.
}

unaffected if these animals were reared from birth to weaning by genetically hypertensive mothers (Azar, Kabat, \& Bingham, 1991; Cierpial \& McCarty, 1987; DiNicolantonio, 1987; DiNicolantonio, Marshall, Nicolaci, \& Doyle, 1986; Murphy \& McCarty, 1989).

A significant feature of the interactions between a mammalian female and her developing young is nutrient exchange. Infants must procure milk from the mother's teat by suckling, and mothers must maintain the production and transfer of milk to their dependent young through physiological and behavioral alterations (Brake, 1991). Milk composition may, in fact, be one aspect of the maternal environment that affects the development of high blood pressure in genetically hypertensive rats. A substantial literature indicates that dietary levels of sodium and calcium have important effects on cardiovascular homeostasis in genetically hypertensive laboratory rats and in humans with essential hypertension (Contreras, 1989; Dustan \& Kirk, 1989; MacGregor, 1985; McCarron, 1985; Sowers, Zemel, Standley, \& Zemel, 1989).

Other electrolytes, such as chloride, magnesium, and potassium, have also been implicated in the etiology of essential hypertension (Dyckner, 1990; Kurtz, Al-Bander, \& Morris, 1987; Whelton \& Klag, 1989). Finally, it has been suggested that an as yet uncharacterized hypertensinogenic factor in milk might be responsible for the development of high blood pressure in SHRs (McMurty, Wright, \& Wexler, 1981).

In the present study, we measured total protein content and concentrations of five electrolytes in milk samples collected from SHR and WKY mothers at 14 days postpartum. We selected this age for milk sampling because it is just prior to the time when rat pups make the transition to the ingestion of solid food (Hall, Cramer, \& Blass, 
1977). In addition, milk concentrations of protein and several electrolytes are generally stable from 10 days postpartum through weaning at 21 days of age (Keen, Lonnerdal, Clegg, \& Hurley, 1981; Luckey, Mende, \& Pleasants, 1954).

\section{METHOD}

Breeding colonies of SHR and WKY rats were maintained in a temperature-controlled vivarium room with a 12:12-h light:dark cycle (lights on from $0700-1900 \mathrm{~h}$ ). The foundation breeding stock for these colonies was originally purchased from Taconic Farms, Germantown, NY. Prior to mating, basal systolic blood pressures were obtained for all SHR and WKY breeders with the use of indirect tail cuff plethysmography (IITC, Inc., Woodland Hills, California). Male and female SHRs were excluded from the breeding colony if their basal systolic blood pressures were less than $150 \mathrm{~mm} \mathrm{Hg}$. Male and female WKYs were excluded from the breeding colony if their basal systolic blood pressures were greater than $130 \mathrm{~mm} \mathrm{Hg}$.

After the measurement of blood pressures, 1 male was placed with two multiparous females of the same strain for at least 1 week in a suspended wire cage $(65 \times 24 \times 18 \mathrm{~cm})$ that was provided with Purina laboratory chow (Formulab 5001) and tap water ad lib. After the 1-week mating period, the females were placed into individual plastic maternity cages $(46 \times 24 \times 20 \mathrm{~cm})$ that were provisioned with laboratory chow, tap water, and bedding material. The cages were checked in the early morning and late afternoon for litters, and the day of birth was designated as Day 0 . All litters were culled to 8 pups on the day after birth.

On the 14th day after birth, the litters were removed from the maternity cages at $0900 \mathrm{~h}$. The pups from each litter were placed into a single plastic container $(15 \times 11 \times 7 \mathrm{~cm})$; all containers were maintained in a pediatric isolette kept at $33^{\circ}-35^{\circ} \mathrm{C}$ and housed in a separate room within the vivarium. At $1500-1600 \mathrm{~h}$, the lactating females received an intraperitoneal injection of oxytocin (Sigma, St. Louis; $0.1 \mathrm{mU}$ in $0.5 \mathrm{ml}$ of $0.9 \%$ saline) and were then lightly anesthetized with Metofane. Milk samples (0.3-0.4 ml) were collected by manual expression from the teats. Milk samples were refrigerated for $1-2$ days at $4^{\circ} \mathrm{C}$ and were then analyzed at the Clinical Chemistry Laboratory of the University of Virginia Health Sciences Center.

Milk concentrations (mmol/L) of $\mathrm{Na}^{+}, \mathrm{K}^{+}, \mathrm{Cl}^{-}$, and $\mathrm{Mg}^{++}$were determined with the use of ion-specific electrodes (Hitachi Model 717 Clinical Analyzer; Boehringer-Mannheim, Indianapolis). With the same clinical analyzer, free $\mathrm{Ca}^{++}$was determined by spectrophotometric measurement of cresol-phthalein complexones with EDTA blanking while total protein was determined by a spectrophotometric biuret. Quintuplicate determinations of all parameters in a pooled milk sample yielded values for each electrolyte and total protein that varied by no more than $5 \%$.

Data are presented as means \pm SEM. Comparisons between strains were made with the use of two-tailed Student's $t$ tests for unpaired data.

\section{RESULTS}

Basal systolic blood pressures of male and female SHRs were significantly greater than corresponding values for WKYs $(p s<.001)$. The systolic blood pressures of all SHR and WKY rats fell within our selection criteria for inclusion in the breeding colony (Table 1).

Table 2 summarizes the total protein and electrolyte contents of milk samples collected from SHR and WKY females at 14 days postpartum. Total protein content was
Table 1

Basal Systolic Blood Pressures $(\mathrm{mm} \mathrm{Hg})$ of SHR and WKY Breeders

\begin{tabular}{lccccc} 
& \multicolumn{2}{c}{ WKY } & & \multicolumn{2}{c}{ SHR } \\
\cline { 2 - 3 } \cline { 5 - 6 }$M \pm S E M$ & Sample Size & & $M \pm S E M$ & Sample Size \\
\hline Males & $106 \pm 4$ & 6 & & $166 \pm 4^{*}$ & 6 \\
Females & $100 \pm 1$ & 12 & & $167 \pm 3^{*}$ & 12 \\
\hline
\end{tabular}

Note-SHR, spontaneously hypertensive; WKY, Wistar-Kyoto. ${ }^{*} p<.001$ (two-tailed $t$ test).

Table 2

Total Protein $(\mathrm{g} / \mathrm{dL})$ and Electrolyte Content $(\mathrm{mmol} / \mathrm{L})$ of Milk Samples Obtained from Lactating WKY and SHR Females at 14 Days Postpartum

\begin{tabular}{lrc}
\hline & $\begin{array}{c}\text { WKY } \\
(n=10)\end{array}$ & $\begin{array}{c}\text { SHR } \\
(n=9)\end{array}$ \\
\hline Total protein & $8.8 \pm 0.1$ & $7.2 \pm 0.2 \ddagger$ \\
$\mathrm{Mg}^{++}$ & $3.4 \pm 0.1$ & $3.4 \pm 0.1$ \\
$\mathrm{Ca}^{++}$ & $67.7 \pm 0.8$ & $58.7 \pm 3.0 \dagger$ \\
$\mathrm{Cl}^{-}$ & $17.0 \pm 1.5$ & $29.4 \pm 4.4^{*}$ \\
$\mathrm{Na}^{+}$ & $32.3 \pm 1.5$ & $47.8 \pm 5.9^{*}$ \\
$\mathrm{~K}^{+}$ & $45.5 \pm 2.2$ & $36.6 \pm 2.3^{*}$ \\
$\mathrm{Na}^{+} / \mathrm{K}^{+}$ & $0.7 \pm 0.1$ & $1.5 \pm 0.4^{*}$ \\
\hline
\end{tabular}

Note-SHR, spontaneously hypertensive; WKY, Wistar-Kyoto. Values are presented as means $\pm S E M .{ }^{*} p<.05$. $\quad t p<.01 . \quad p<.001$. (Two-tailed $t$ test.)

reduced significantly in milk samples of SHR females $(p<.001)$. The milk from SHR females also contained significantly less $\mathrm{Ca}^{++}(p<.01)$ and $\mathrm{K}^{+}(p<.05)$ than did the milk from WKY females. In contrast, the milk concentrations of $\mathrm{Na}^{+}$and $\mathrm{Cl}^{-}$as well as the $\mathrm{Na}^{+} / \mathrm{K}^{+}$ratio were elevated significantly in SHR females. However, the milk levels of $\mathrm{Mg}^{++}$were similar for SHR and WKY females.

\section{DISCUSSION}

The present findings provide important new information regarding the diet available to preweanling genetically hypertensive rat pups. We have demonstrated that SHR females at 14 days postpartum produce milk that contains elevated levels of $\mathrm{Na}^{+}$and $\mathrm{Cl}^{-}$and reduced levels of $\mathrm{Ca}^{++}, \mathrm{K}^{+}$, and protein. These strain differences in milk electrolytes may represent an important dietary contribution to the observed increases in arterial pressure of SHR pups from the time between birth and weaning (Gray, 1984). The reductions in milk protein may explain in part the substantial body weight differences between SHR and WKY pups during the preweanling period (Cierpial \& McCarty, 1987).

Our data for milk electrolytes are in general agreement with reports by others. For example, DiNicolantonio et al. (1986) noted that the milk $\left[\mathrm{Na}^{+}\right] /\left[\mathrm{K}^{+}\right]$of SHR females was significantly greater than for normotensive SpragueDawley females, although absolute values for the two electrolytes were not reported. In addition, Azar et al. (1991) reported that milk samples collected from SHR females 
at $3,7,15$, and 19 days postpartum had elevated levels of $\mathrm{Na}^{+}$when compared with milk samples from matched WKY controls. In contrast to our results, these investigators found no differences in milk content of $\mathrm{K}^{+}$at any of the four sample points. Finally, Dene and Rapp (1985) found that milk levels of $\mathrm{Na}^{+}$were elevated and milk levels of $\mathrm{K}^{+}$were reduced in inbred Dahl salt-sensitive hypertensive rats in comparison with the milk levels in normotensive salt-resistant controls.

It is well known that dietary levels of sodium and potassium have important effects on cardiovascular homeostasis (Dustan \& Kirk, 1989; Gavras \& Gavras, 1989; McCarron, 1986, 1989; Zicha, Kunes, \& Jelinek, 1986). Other electrolytes, such as chloride, potassium, and magnesium have also been shown to have important effects on the cardiovascular system (Dyckner, 1990; Kurtz, Al-Bander, \& Morris, 1987; Whelton \& Klag, 1989). In addition, increases in dietary sodium exacerbate and increases in dietary calcium ameliorate the development of hypertension in young, postweaned SHRs (Gavras \& Gavras, 1989; Hatton, Muntzel, McCarron, Pressley, \& Bukoski, 1988; Muntzel, Hatton, Metz, \& McCarron, 1989).

Studies done with dietary electrolyte manipulations during the preweanling period have limited utility in hypertensive rats because milk electrolyte content is not altered in lactating female rats in response to changes in dietary electrolytes (Azar et al., 1991). In addition, manipulation of maternal dietary electrolytes may influence offspring blood pressure development indirectly because of diet-induced changes in the maternal behavior and/or cardiovascular function. Finally, the test diet could be ingested directly by the hypertensive rat pups prior to weaning.

Cross-fostering studies of hypertensive and normotensive pups provide an indication that the milk provided by hypertensive mothers to their pups represents an important preweanling influence on full expression of the hypertensive phenotype. SHR pups reared from birth to weaning by WKY or Sprague-Dawley normotensive foster mothers have significant reductions in arterial pressure in adulthood when compared with SHR pups reared by their natural mothers or by SHR foster mothers (Cierpial, Konarska, \& McCarty, 1990; Cierpial \& McCarty, 1987, 1991). Similarly, SS/Jr pups reared by normotensive SR/Jr foster mothers have significant reductions in adult blood pressures when compared with control SS/Jr rats reared by their natural mothers or by SS/Jr foster mothers (Murphy \& McCarty, 1989). The influence of the normotensive foster mother appears to be limited to the first 2 postnatal weeks. Our recent studies indicate that crossfostering SHR pups to a WKY foster mother for Postnatal Days 1-7 or 1-14 has an impact on adult blood pressures that is comparable to the effect observed in SHR pups cross-fostered to WKY mothers for the entire 3-week preweanling period (McCarty, Cierpial, Murphy, Lee, \& Fields-Okotcha, 1992). This study indicates that the blood-pressure-lowering effect of cross-fostering corresponds to the time during the preweanling period when pups receive all of their nourishment from the mother.
Much of the literature on electrolytes and blood pressure regulation takes the limited view that a single electrolyte is responsible for the development of hypertension. The present results suggest an alternative view; that is, a combination of electrolyte alterations in milk may provide the stimulus for the development of high blood pressure in genetically susceptible animals. Only by determining a milk electrolyte profile could such relationships be revealed. Additionally, consideration must be given to the occurrence of other hypertensinogenic factors in milk, including peptide hormones that affect the developing cardiovascular system (Hazum, 1983; Koldovsky, 1980).

\section{REFERENCES}

AzAr, S., KABAT, V., \& Bingham, C. (1991). Environmental factor(s) during suckling exert long-term effects upon blood pressure and body weight in spontaneously hypertensive and normotensive rats. Journal of Hypertension, 9, 309-327.

BlizaRD, D. A. (1992). Nature/nurture and the nature of nurture in the etiology of hypertension. Experientia, 48, 311-314.

Brake, S. C. (1991). New information about early feeding and motivation: Techniques for recording sucking in infant rats. In $\mathbf{H}$. N. Shair, G. A. Barr, \& M. R. Hofer (Eds.), Developmental psychobiology: New methods and changing concepts (pp. 32-46). New York: Oxford University Press.

Cierpial, M. A., Konarska, M., McCarty, R. (1990). Matemal influences on the sympathetic-adrenal medullary system in spontaneously hypertensive rats. American Journal of Physiology, 258, H1312-H1316.

Cierpial, M. A. , \& MCCARTY, R. (1987). Hypertension in SHR rats: Contribution of maternal environment. American Joumal of Physiology, 253, H980-H984.

Cierpial, M. A., \& MCCarty, R. (1991). Adult blood pressure reduction in spontaneously hypertensive rats reared by normotensive Sprague-Dawley mothers. Behavioral \& Neural Biology, 56, 262-270.

Contreras, R. J. (1989). Differences in perinatal $\mathrm{NaCl}$ exposure alter blood pressure levels of adult rats. American Journal of Physiology, 256, R70-R77.

DENE, H., \& RAPP, J. P. (1985). Lack of effects of maternal salt intake on blood pressure of offspring in Dahl salt-sensitive rats. Clinical \& Experimental Hypertension-Theory \& Practice, A7, 1121-1133.

DiNicolantonio, R. (1987). Blood pressure and salt appetite of crosssuckled spontaneously hypertensive and normotensive rats. Journal of Hypertension, 5, 413-416.

DiNicolantonio, R., Imal, T., Murakami, K., Yamord, Y. (1991). Hypertension: Genes, environment, or both? News in Physiological Sciences, 6, 174-177.

DiNicolantonio, R., Marshall, S. J., Nicolaci, J. A., \& Doyle, A. E. (1986). Blood pressure and saline preference of cross-suckled genetically hypertensive and normotensive rats: Role of milk electrolytes. Joumal of Hypertension, 4 (Suppl. 3), S253-S254.

Dustan, H. P., \& KIRK, K. A. (1989). Corcoran lecture. The case for or against salt in hypertension. Hypertension, 13, 696-705.

DYCKNER, T. (1990). Relation of cardiovascular disease to potassium and magnesium deficiencies. American Joumal of Cardiology, 65, $44 \mathrm{~K}-46 \mathrm{~K}$.

Gavras, H., GAvras, I. (1989). Salt-induced hypertension: The interactive role of vasopressin and the sympathetic nervous system. Journal of Hypertension, 7, 601-606.

GELLER, R. (Ed.) (1977). Spontaneous hypertension: Its pathogenesis and complications (Department of Health, Education and Welfare Publication No. 77-1179). Washington, DC: U.S. Government Printing Office.

GrAY, S. D. (1984). Spontaneous hypertension in the neonatal rat. Clinical \& Experimental Hypertension-Theory \& Practice, A6, 755-781.

Hall, W. G., Cramer, C. P., \& Blass, E. M. (1977). Ontogeny of suckling in rats: Transitions toward adult ingestion. Joumal of Comparative \& Physiological Psychology, 91, 1141-1155. 
Hatton, D. C., Muntzel, M., McCarron, D. A., Pressley, M., \& Bukoski, R. D. (1988). Early effects of dietary calcium on blood pressure, plasma volume, and vascular reactivity. Kidney International, 34 (Suppl. 25), S16-S18.

Hazum, E. (1983). Hormones and neurotransmitters in milk. Trends in Pharmacological Sciences, 4, 454-456.

Keen, C. L., Lonnerdal, B., ClegG, M., \& Hurley, L. S. (1981). Developmental changes in composition of rat milk: Trace elements, minerals, protein, carbohydrate and fat. Journal of Nutrition, 111 , 226-230.

Koldovsky, O. (1980). Hormones in milk. Life Sciences, 26, 1833-1836.

Kurtz, T. W., Al-Bander, H. A., \& Morris, R. C. (1987). Saltsensitive essential hypertension in men: Is the sodium ion alone important? New England Journal of Medicine, 317, 1043-1048.

LovenberG, W., Simpson, F. O., \& YAMORI, Y., (Eds.) (1986). Contribution of hypertensive rat models to medicine. Joumal of Hyper tension, 4 (Suppl. 3), S1- S541.

Luckey, T. D., Mende, T. J., \& Pleasants, J. (1954). The physical and chemical characterization of rat's milk. Journal of Nutrition, 54 , 345-359.

MAcGregor, G. A. (1985). Sodium is more important than calcium in essential hypertension. Hypertension, 7, 628-637.

MCCARRON, D. A. (1985). Is calcium more important than sodium in the pathogenesis of essential hypertension? Hypertension, 7, 607-627.

MCCARRON, D. A. (1986). The calcium deficiency hypothesis of hypertension. Annals of Internal Medicine, 105, 947-955.

MCCARRON, D. A. (1989). Calcium metabolism and hypertension. Kidney International, 35, 717-736.
McCarty, R., Cierpial, M. A., Murphy, C. A., Lee, J. H., \& FIELDS-OKотсHA, C. (1992). Maternal involvement in the development of cardiovascular phenotype. Experientia, 48, 315-322.

McMurty, J. P., Wright, G. L., \& WeXler, B. C. (1981). Spontaneous hypertension in cross-suckled rats. Science, 211, 1173-1175.

Muntzel, M. S., Hatton, D. C., Metz, J. A., McCarron, D. A. (1989). Dietary calcium alters blood pressure in neonatal spontaneously hypertensive rats. American Journal of Hypertension, 2, 158-162.

MURPhy, C. A., \& McCARTY, R. (1989). Maternal environment and development of high blood pressure in Dahl hypertensive rats. American Journal of Physiology, 257, H1396-H1401.

Окомото, К. (Ed.) (1972). Spontaneous hypertension: Its pathogenesis and complications. Tokyo: Igaku Shoin.

Rascher, W., Clough, D., \& Ganten, D. (Eds.) (1982). Hypertensive mechanisms: The spontaneously hypertensive rat as a model to study human hypertension. Stuttgart: F. K. Schattauer.

Sowers, J. R., Zemel, M. B., Standley, P. R., \& Zemel, P.C. (1989). Calcium and hypertension. Journal of Laboratory \& Clinical Medicine, 114, 338-348.

Whelton, P. K., \& KLAG, M. J. (1989). Magnesium and blood pressure: Review of the epidemiologic and clinical trial experience. American Journal of Cardiology, 63, 26G-30G.

ZichA, J., KUNES, J., \& JELINEK, J. (1986). Experimental hypertension in young and adult animals. Hypertension, 8, 1096-1104.

(Manuscript received September 9, 1992; revision accepted for publication September 23, 1992.)

\section{Notice}

\section{Nominations for the Editorship of Psychobiology}

Nominations are solicited for the editorship of Psychobiology. The term of the present editor, Paul E. Gold, expires at the end of 1994. The new editor will begin an official 4-year term January 1, 1995. It is expected that the Publications Committee of the Psychonomic Society will make the appointment by June 1993.

Nominations must be submitted by April 30, 1993.

Nominations (including self-nominations) should be sent to:

Douglas L. Medin

Department of Psychology

Northwestern University

2029 Sheridan Road

Evanston, IL 60208 